\title{
The Design of Lightweight UAV Classification Accelerating Ectromagnetic Launcher
}

\author{
Hailong Wang, Jingyu Yang, Zhijie Zhang, Chen Li, Zhihao Zhang, Guangliang Xu, Bowen Zhang and Gang Wang \\ Laboratory of Space Solar Power Station Dynamics and Control, Innovation Studio of Marine-Space Science \& Technology, \\ Faculty of Aerospace Engineering, Shenyang Aerospace University, Shenyang, China
}

\begin{abstract}
In this paper, a kind of lightweight UAV classification accelerating Ectromagnetic Launcher (EML) has been designed. Firstly, 20kg of lightweight UAV ejection problem has been analyzed in the civil field. Secondly, the advantages and disadvantages of different modes of EML have been considered for lightweight unmanned aerial vehicle, and later an innovative design of classification accelerating EML has determined. It has chain transmission structure and has advantages of module design, general fitness. Thirdly, the kinematics analysis and the ejection process of UAV EML have been discussed. Based on requirement of parameters of UAV EML, overall design of EML, structure design of EML and components of EML system have been determined. Finally, the parts of model of EML system have been designed using CATIA software.
\end{abstract}

Keywords-module design; structure design; chain transmission structure; EML

\section{INTRODUCTION}

Compared to manned aircrafts, UAV have their special advantages and irreplaceable functions[6].With civilian UAV more widely use and more far-reaching impact, innovative research of light UAV catapult device attracts more and more people's attention[2].Therefore, there is still a need for more capable aircraft, mainly in terms of payload and endurance, in both military and civilian markets[4].So the market need innovative research of drive mode during the UAV electric ejection process.

The technical solution of UAV has the following features: good controllability; simple thrust control; high precision; long operating life; low cost; strong adaptability, repeatability, and imperceptibility[1].Based on the results of the simulation, respective take-off criteria must be drafted considering different types of aircraft and different take-off load cases, all of which must be matched to parameters relevant to catapult take-off[7].Assisted launch has the potential of reducing the required runway length, reducing noise near airports and improving overall aircraft efficiency through reducing engine thrust requirements[5]. Additionally, chain drive sprockets with a straight tooth profile have a number of advantages in comparison with other profiles, and are therefore widely used[3].So in this paper, I choose the chain drive as a catapult transmission form.

\section{ANALYSIS OF UAV EJECTION PROCESS}

UAV catapult aircraft taxiing along the track, rotating torque generated by the motor is limited to the rails, and is offset by the process air and kinetic friction of power and drones, UAV are therefore roll process linear acceleration of the process.

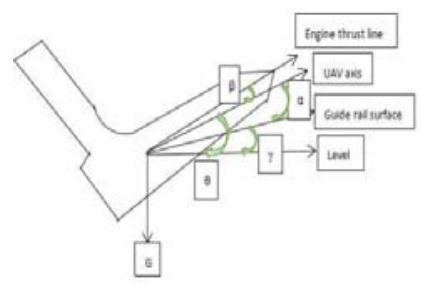

FIGURE I. KINEMATIC ANALYSIS DIAGRAM OF UAV GUIDE RAIL TAKEOFF

UAV take-off relationship between the angle of attack and the launch angle is $\theta=\alpha+\gamma$. For general UAV, launch angle setting is appropriate in the range of 15 to 35 degrees. From the knowledge of physics can be derived UAV takeoff speed and sliding acceleration formula

$$
\begin{gathered}
v_{\mathrm{c}}=\sqrt{\frac{2\left[\int_{0}^{s}\left(\frac{9550 P}{n d}+T_{2}-\mu m g \cos \theta-F_{d}\right) d s-m g s \sin \theta\right]}{m}} \\
a=\frac{9550 P}{n d m}+\frac{T_{2}}{m}-\mu g \cos \theta-\frac{F_{d}}{m}
\end{gathered}
$$

In the above formulas, $\mu$ is the dynamic friction factor of the guide;T2,UAV thrust produced by the engine; $\mathrm{P}$, output power; n, speed; d, force-arm;m, the quality of UAV; s, the length of the rail; Fd, UAV suffered air resistance.

\section{OVERALl Design of ThE UAV EJECTION System}

\section{A. The Ideas Of Device Design}

The device with more adaptability and versatility resistance can adjust takeoff angle of attack and increase and decrease transmission modules for different UAV takeoff weight, so as to achieve maximum acceleration roll and the emitter shortest time. Furthermore, removable design makes the device easy to carry and have greater mobility. 


\section{B. Architecture Overview}

UAV electric ejection device consists of basic structure, power systems, suspension systems, safety protection system. s styled.

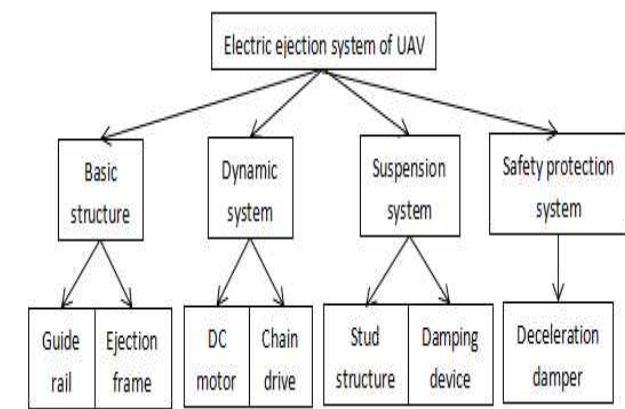

FIGURE II. THE OVERALL STRUCTURE OF THE DEVICE

1) Basic structure: The basic structure is composed by catapult frame and two parallel to each other and the emission angle adjustable rails. The main role of catapult frame is to let UAV accelerated roll to get enough speed to get rid of gravity and achieve take-off.

2) Power system: Power system is composed of several DC motor and chain drive mechanism. Specifically, both sides of the guide were distributed a chain drive module, to form a linkage. Two same specifications DC motors operated simultaneously and with equal speed are placed at head and tail of each chain drive modules. Motors drive chain drive mechanism by bearing.

3) Suspension system: The suspension system is the connection and damping device between the rail and the ground. There are a height adjustable stud connection in the front of the guide and a damping device which is used for rapidly decaying the reaction energy catapult suffered below the connection part. Support frame can be fixed to the ground or trailer frame to ensure the stability of the ejection process in the rear of the guide, and it is easy to install and disassemble.

4) Security system: Security system is mainly constituted by the spring damper deceleration, which can rapidly decay the speed of catapult frame separated from UAV .So the catapult frame always is restricted on the rail to avoid danger.

\section{B. General Assembly}

The whole structure of the device is reasonable and coordinated, and is suitable for the launch of UAV.
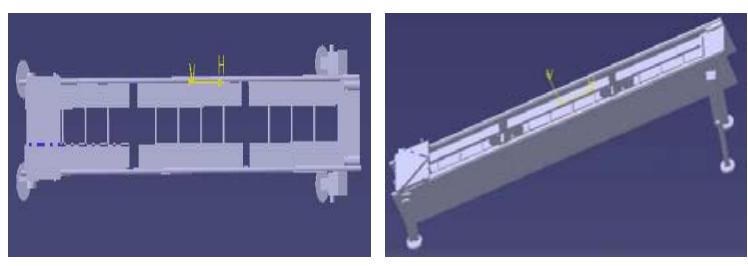

FIGURE III. THE THREE-DIMENSIONAL MODEL DIAGRAM.

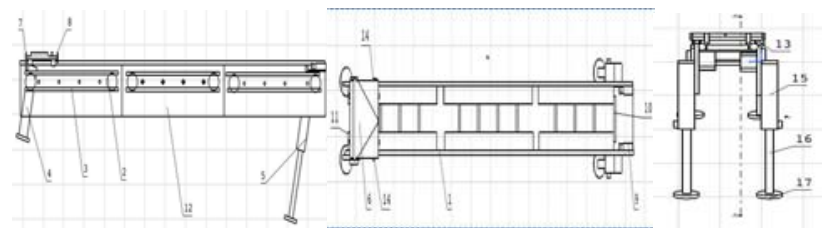

FIGURE IV. POSITIVE,TOP AND LEFT VIEW OF THE CATAPULT

In the all views above, different number of digits represent different structure names:

1-Guide rail;2-DC motor;3-Chain transmission device;

4-Rear bracket;5-Front bracket;6-Ejectionframe;7-Block;

8-Buckle;9-Deceleration damper;10-Release mechanism;

11-Locking mechanism;12-Chain drive module;

13-Slide block;14-Limit block;15-Stud structure;

16-Spring shock absorber;17-Support seat.

\section{DETAILED DESIGN OF EACH PART OF THE DEVICE}

\section{A. Dc Motor Selection}

Taking into account the device is a light UAV, that is, less than $100 \mathrm{~kg}$ of UAV, here select ZYT series DC permanent magnet motor to fully meet the design requirements.

\section{B. Chain Drive Design}

The device adopts parallel chain transmission structure. And each sprocket is driven by the same model and the same rotating speed motors, so that the speed of the chain is 2 times to the speed of the motor, and the transmission efficiency is improved.

1) Sprocket tooth number: From the engineering practice, the choice of the number of sprocket teeth is roughly between 17 and 114.The number of sprocket teeth is preferred: $17,19,21,23,25,38,57,76,95$ and 114 .

2) Chain pitch and the number of rows: In order to make the structure compact and prolong the service life, we should choose the single row chain with smaller pitch.

3) Drive ratio: General chain drive ratio should be less than 7.The size of the device sprocket have the same number of teeth, then the drive ratio is 1 , to meet the requirements.

\section{Guide Design}

1) Material selection: In this design, the length of the guide rail is close to $3 \mathrm{~m}$, which requires the guide rail bearing capacity and reduce its weight, so the guide rail selection of aluminum alloy 5000 series.

2) Section shape selection: The choice of the guide rail section shape generally concludes rectangle, I-shape, round and so on. The bending and torsion performance of circular section is good, and the contact area between the ejection frame and the guide rail is minimum. So derailment phenomenon is not easy to happen. So the guide chooses circular cross section. 
3) The selection of the length and width: In order to facilitate the transport of the ejection device, the guide rail is arranged into three sections. Each level acceleration rail is $1 \mathrm{~m}$ and is driven by two groups of four motors of the same type. The final three speed rail is about $3 \mathrm{M}$, capable of firing $20 \mathrm{~kg}$ of UAV. Unified design for rail width is about $180 \mathrm{~mm}$, equivalent to the UAV fuselage width.

\section{Catapult Frame Structure Design}

Catapult frame is used to connect guide rail and UAV, which achieve accelerated motion along the guide rail driven by a chain drive mechanism.

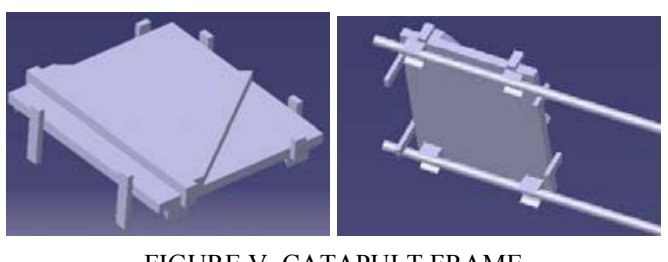

FIGURE V. CATAPULT FRAME

1) Catapult frame and rail connection: As the guide rail selects a circular section shape, and in order to fit with the guide rail and avoid the risk of derailment in the process, it is required to install the bottom of the ejection frame as shown in the figure below the four slider.

2) Catapult aircraft and UAV connection: The around sides of the ejection frame is provided with a limiting block to prevent the swing of UAV taxiing process. The rear part of the ejection frame is provided with a stop block to prevent the unmanned aerial vehicle from moving backward. The front end of the ejection frame is a buckle which limits UAV forward movement.

\section{E. Suspension System Design}

A suspension system which consists the front bracket and the rear bracket is used to connect the rail with the ground or frame.

1) Front bracket design: The front bracket adopts the design of integral shaft, which from top to bottom are stud structure, spring damper and bearing seat. The supporting seat through bolts on the trailer frame or on the ground.

2) Rear bracket design: The function of rear bracket is to provide support for the ejection device. This requires the structural strength of rear bracket material larger so we choose $3 \mathrm{~mm}$ thick steel plate and an additional reinforcement plate to enhance the strength.

\section{F. Deceleration Damper Design}

The deceleration damper is installed at the front end of the guide rail, which has a deceleration effect on the ejection frame after releasing UAV. According to the symmetrical structure of the guide rail and the ejection frame, the damper is designed as a pair of spring speed reducer to buffer the energy of the ejection frame, and is welded at the end of the guide rail.

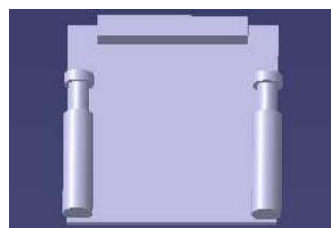

FIGURE VI. DECELERATION DAMPER SCHEMATICSTATIC

\section{STATIC STRENGTH OF COMPONENTS}

\section{A. Static Strength Analysis Of Guide Rail}

In the UAV ejection process, catapult rail can be simplified as a beam, UAV and ejection frame on the rail pressure can be simplified into a concentrated load on.

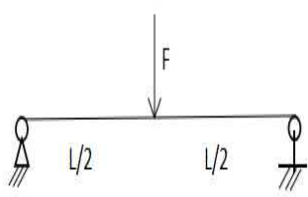

\section{FIGURE VII. SIMPLIFIED FORCE DIAGRAM OF RAIL}

The following is a study of a single guide rail. The length of the guide rail is $\mathrm{L}=3 \mathrm{~m}$, the diameter of the circular cross section is $d=20 \mathrm{~mm}$, the concentration is about $\mathrm{F}=0.5 \mathrm{G}=50 \mathrm{~N}$, and the effect is at the middle point of the beam.

It is known that the dangerous section of the guide rail is the middle section of the beam, which can bear the maximum tensile stress. The maximum bending moment of the beam is

$$
M_{\max }=\frac{F L}{4}=37.5 \mathrm{~N} / M
$$

As the guide rail material for the 5000 series of aluminum alloy, the tensile strength of the material is about $[\sigma]=270 \mathrm{MPa}$.

The inertia moment of circular cross section is calculated:

$$
I=\frac{1}{64} \pi d^{4}=7.854 \times 10^{-9} \mathrm{~m}^{4}
$$

The maximum bending tensile stress of the dangerous cross section is

$$
\sigma_{\max }=\frac{M_{\max } d / 2}{I}=47.75 M P_{a}<[\sigma]
$$

From the above results, it can be known that the maximum tensile stress of the dangerous section of the guide rail is less than the allowable stress of the material, which can meet the strength requirements of the structure. 


\section{B. Static Stiffness Analysis Of Catapult Frame}

In the ejection frame rail end contact impact damper, appears the maximum deformation, in order to avoid structural damage, need to calculate the maximum deformation by finite element software.

Known DC motor rated speed $n=3000 \mathrm{r} / \mathrm{min}$, rated output power $\mathrm{P}=1.2 \mathrm{KW}$, the output torque of the motor is

$$
M=\frac{9550 P}{n}=3.82 N \cdot M
$$

And the chain drive module of the arm to be $d=20 \mathrm{~mm}$,

The thrust produced by the motor on the launch pad is

$$
T_{1}=\frac{M}{d}=191 N
$$

The ejection frame can be simplified as a $180 \mathrm{~mm} * 180 \mathrm{~mm}$ pull plate element in the analysis. Then we carry out the finite element analysis of the ejection frame through software Patran.
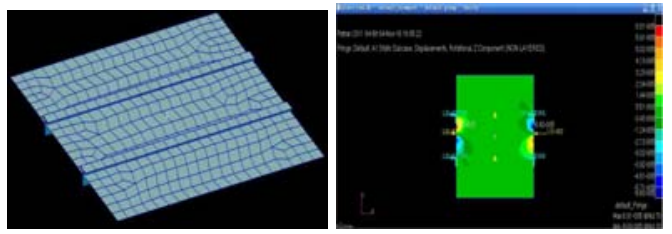

FIGURE VIII. DEFORMATION DIAGRAM OF FRAME

The figure indicates that the maximum deformation of the ejection frame is $6.81 \times 10-5 \mathrm{~mm}$, which is almost negligible, so that the stiffness of the ejection frame is satisfied in the whole process of the whole UAV.

\section{Static Stiffness Analysis Of Wing}

We need to ensure the strength of the wing under overload conditions during the acceleration of the UAV. Desirable UAV takeoff speed $\mathrm{v}=15 \mathrm{~m} / \mathrm{s}$, wing area of $\mathrm{S}=1$ square meters, the atmospheric pressure $\mathrm{P}=1.225$, the lift coefficient is 1.439 , calculated

$$
Y=\frac{1}{2} \rho v^{2} S C_{L}=198 N \approx 2 G
$$

The aircraft is subjected to an overload of about 2 times. The below diagrams show that the maximum deformation of the wing root is negligible, it can be seen that the strength of the wing will not exceed the allowable value.
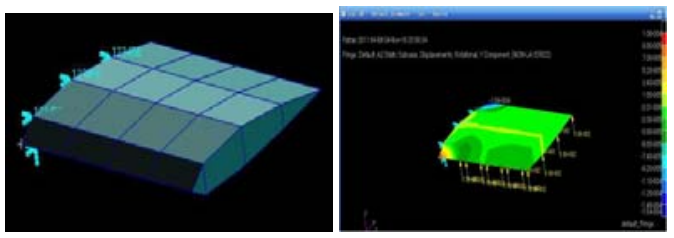

FIGURE IX. DEFORMATION DIAGRAM OF WING

\section{CONCLUSION}

The main findings of this article are as follows: Firstly, I complete the kinematic analysis of UAV ejection process. Then, according to the performance parameter requirements of the Launching system, I finish the overall design of the device and detailed design of components. Finally, I used the CATIA software to carry out the three-dimensional modeling of the ejection device, showing the connection of the components of the device and the relationship of the assembly. I also used the Patran software to analysis the static strength of the important structures.

This work still has some shortcomings and need to be further improved and perfected in future studies. On the one hand, the ejection device can be further made into a folding type structure so that the device is more convenient for transportation and maintenance. On the other hand, the device can only launch a maximum weight of $20 \mathrm{~kg}$ uav. We can increase the launch weight by strengthening the structural strength or the optimum design of the device.

\section{ACKNOWLEDGMENT}

This project is supported by the innovation and entrepreneurship training program for college students "Emote operation, display and control of electromagnetic launcher(Grant No.X1610318)";National Natural Science Foundation of China(Grant No. 51605308)“Co-evolution of fractional order coupled structure vibration-attitude dynamic and control of spacecraft"; The Liaoning Province doctor Science Research Fund Project "Co-evolution of fractional order coupled structure vibration-attitude dynamic and control of China Space Station"(Grant No. 201601178); The Liaoning Province "13th Five Year Plan" Higher Education Research Fund Project "Teaching quality monitoring system and safeguard mechanism research on Aerospace engineering majors"(Grant No. GHZD160012); The Liaoning Province Department of Education Fund Project "Study of fractional order coupled structure vibration-attitude dynamic and control of spacecraft"(Grant No. L2015414); The Liaoning Province Department of Education Fund Project "Research and practice on specialty of aerospace engineering based on recognition for engineering education"(Grant No.030201619);"Exploration and Practice of 'Theory+ Interesting+ Research' Innovative Teaching Mode"(Grant No.YJS2014-11);"Research on Intelligent Integrated Control of Coupling between Space Solar Power Station Structure Vibration and Attitude Control (Grant No.13YB22)";"Simulation and experimental platform design of virtual control of hypersonic aircrafts(Grant No.DX501312)";"Health monitoring system design of attitude-structure vibration of in-orbit spacecraft"(Grant No. 201610143050);"Design and analysis of intelligent metamaterial cloaking structure system(Grant No.X1610317)”.

\section{REFERENCES}

[1] T. G. Jun, K. B. Quan, and W. H. Xing, "Dynamic sensorless detection of linear electromagnetic UAV launch," IEEE Transactions on Plasma Science, v 39, n 1 PART 1, p 399-404, January 2011. 
[2] P. David, and D. J. Andres,"In situ sampling of volcanic emissions with a UAV sensorweb: Progress and plans," Lecture Notes in Computer Science (including subseries Lecture Notes in Artificial Intelligence and Lecture Notes in Bioinformatics), v 8964, p 16-27, 2015.

[3] G. K. Ryabov, V. I. Zhirekhin, A. V. Ternovoi, and V. I. Mazur, "On the problem of tooth profiling of chain drive sprockets, "Soviet engineering research, v 9, n 3, p 39-41, 1989.

[4] A. Cabarbaye, R. L. Leal, and P. Fabiani, "VTOL aircraft concept, suitable for unmanned applications, with equivalent performance compared to conventional aeroplane,"2016 International Conference on Unmanned Aircraft Systems, ICUAS 2016, p 219-226, June 30, 2016

[5] L. Bertola, T. Cox, P. Wheeler, S. Garvey, and H. Morvan, "Electromagnetic launch systems for civil aircraft assisted take-off," Archives of Electrical Engineering, v 64, n 4, p 535-546, December 1, 2015.

[6] D. Liu, G. Liu,and G. Hong, "Analysis of onboard takeoff and landing characteristics for unmanned aerial vehicles," AIAA Modeling and Simulation Technologies Conference, 2016.

[7] M. Zhang, H.Nie, and Z. He, "Parameter optimization of nose landing gear considering both take-off and landing performance of catapult takeoff carrier-based aircraft, "Transactions of Nanjing University of Aeronautics and Astronautics, v 33, n 2, p 187-198, April 1, 2016. 